\title{
Desenvolvimento de Maionese com Sabor Regional
}

\author{
Flávia I. R. O. Araújo, Marina S. Araújo, Adriana A. Carvalho \& \\ Karolline F. Siqueira
}

A maionese é uma típica emulsão semissólida de óleo em água. Em sua composição comercial típica geralmente encontram-se, além do óleo, gema de ovo, vinagre, sal e especiarias, especialmente, a mostarda. Este trabalho objetivou desenvolver uma maionese sabor regional. O óleo de soja foi substituído parcialmente por óleo de pequi. A maionese foi analisada físico-química, microbiológica e sensorialmente por meio do teste de aceitação. O produto apresentou excelente composição nutricional, boa aceitação sensorial e vida útil de aproximadamente 94 dias.

Palavras-chaves: pequi; caracterização; aceitação.

Mayonnaise is a typical semi-solid emulsion of oil in water. In a typical commercial composition usually are, in addition to oil, egg yolk, vinegar, salt and spices, especially mustard. This work aimed to develop a regional flavor mayonnaise . The soybean oil was substituted partially pequi oil . The mayonnaise was analyzed physico- chemical, microbiological and sensory through the acceptance test. Product presented excellent nutritional composition, good acceptance and sensory life useful approximatif of 94 days .

Key words: pequi; characterization; acceptance. 


\section{Introdução}

A maionese é um dos molhos mais antigos, tradicionais e consumidos em nível mundial. É um alimento bastante consumido em residências e também em restaurantes para preparar sanduíches, saladas e outros pratos frios ${ }^{1}$. Tradicionalmente, a maionese é produzida em bateladas pela lenta adição de óleo à fase aquosa sob vigorosa agitação, criando um sistema de emulsão óleo em água ${ }^{2}$.

A maionese é uma típica emulsão semissólida de óleo em água. Em sua composição comercial típica geralmente encontram-se, além do óleo, gema de ovo, vinagre, sal e especiarias, especialmente a mostarda. A gema do ovo é o ingrediente mais crítico para a estabilidade da maionese pois tem comportamento anfótero ${ }^{3 ;}$.

Nos Estados Unidos, a Lei 21 CFR 169.1405 exige que a maionese tenha, pelo menos, $65 \%$ de óleo vegetal em massa. Dessa maneira, as maioneses encontradas no mercado têm teores de óleo entre 70 e $80 \%$. O mercado para este produto está baseado em diferentes e interessantes sabores e aromas. Mesmo assim, este mercado está preocupado em utilizar outros ingredientes, e versões "mais saudáveis" têm sido desenvolvidas ${ }^{6}$.

No Brasil, a maionese é definida pela RDC $n^{\circ}$ 276/20057 como o produto cremoso em forma de emulsão estável, óleo em água, preparado a partir de óleo(s) vegetal(is), água e ovos, podendo ser adicionado de outros ingredientes desde que não descaracterizem o produto. Essa resolução estabelece ainda que o produto deve ser acidificado. Como a legislação brasileira não estabelece um teor mínimo de óleo para a fabricação da maionese, a maior parte das maioneses tradicionais encontradas no mercado brasileiro tem como ingrediente em maior quantidade a água, seguida pelo óleo vegetal.

Já é comprovado que a quantidade e o tipo de gordura ingerida pelo homem influenciam no desenvolvimento de doenças crônicas. Este fato vem provocando um aumento na preocupação do consumidor quanto a orientações nutricionais sobre a ingestão de gordura, e uma forte tendência ao consumo de produtos "low-fast", gerando pressão na indústria de alimentos para reduzir a quantidade de gordura ou substituí-la por outras mais saudáveis nos produtos alimentícios. Dessa forma, devido à composição da maionese, muitos estudos têm sido realizados para tentar substituir alguns ingredientes. Dentre esses, a gema do ovo é um dos ingredientes com potencial para substituição na tentativa de reduzir o teor de colesterol da maionese ${ }^{8 ; 9}$. Outros têm tentado substituir a fração lipídica na tentativa de obter uma maionese com as características sensoriais típicas, mas com reduzido valor energético ${ }^{10 ; 11 ; 12 ; 13 ; 14}$.

Nesse ínterim, o óleo de pequi torna-se uma alternativa interessante para compor parte da fração lipídica para a elaboração de maionese. O pequi (Caryocar brasilense Camb.) apresenta alta ocorrência, grande volume de comercialização e características sensoriais peculiares. A polpa de pequi é amplamente utilizada em preparações regionais e, no que diz respeito ao seu valor nutricional, caracteriza-se pelo alto teor de fibras, carotenoides e lipídeos. $\mathrm{O}$ azeite de pequi possui coloração vermelho-alaranjada devido à presença de pigmentos carotenoides ${ }^{15}$. A presença de carotenoides nesse azeite sugere ainda outros tipos de utilização, como na fabricação de produtos que não necessitem de tratamento térmico, evitando, assim, a degradação deste nutriente. Assim, este projeto teve como objetivo o desenvolvimento de uma maionese de sabor regional e que apresentasse características de saudabilidade como substituição parcial de ingredientes gordurosos e acréscimo de ingredientes que conferisse aspectos de funcionalidade. Para isso, foi proposta a substituição parcial do óleo de soja por óleo de pequi.

\section{Materiais e Métodos}

\section{INGREDIENTES}

Todos os ingredientes usados para preparar a maionese, tais como óleo de soja, óleo de pequi, gema de ovo em pó, amido modificado, goma xantana, sal iodado, aroma de maionese, aroma de frango com pequi, EDTA, açúcar, ácido cítrico, vinagre, mostarda em pó, sorbato, alecrim e páprica doce foram adquiridos a partir de um mercado local.

\section{FORMULAÇÃO DA MAIONESE}

A maionese elaborada com óleo de pequi foi preparada utilizando em sua formulação $22,10 \%$ de óleo de soja e $2,88 \%$ de óleo de pequi, amido modificado, goma xantana, vinagre, ácido cítrico, sal, açúcar, gema de ovo, aroma, sorbato, EDTA, alecrim, mostarda e páprica doce. 


\section{ANÁLISES FÍSICO-QUÍMICAS}

Umidade, cinzas e lipídeos totais foram determinados conforme $\mathrm{IAL}^{16}$. Para a determinação de proteínas foi utilizada a metodologia proposta por $\mathrm{AOAC}^{17}$. Os carboidratos totais foram obtidos através da subtração dos valores de umidade, cinzas, lipídeos totais e proteína ${ }^{18}$. Os minerais cálcio, ferro, fósforo, magnésio, potássio e sódio foram determinados segundo a metodologia preconizada pela $\mathrm{AOAC}^{19}$. O perfil de ácidos graxos, bem como o teor de ácidos graxos livres e o índice de iodo foram determinados conforme $\mathrm{AOCS}^{20}$. Os teores de betacaroteno $^{21}$ e vitamina $\mathrm{E}^{22}$ também foram determinados.

\section{ANÁLISES MICROBIOLÓGICAS}

Para avaliação da conformidade microbiológica da maionese, estabelecida conforme a Resolução $\mathrm{n}^{\circ} 12$ de 02 de janeiro de 2001, da Agência Nacional de Vigilância Sanitária (ANVISA), foram realizadas análises para determinação de Salmonella (25g), coliformes termotolerantes $(\mathrm{NMP} / \mathrm{g})$, contagem total de aeróbios mesófilos (UFC/g) e contagem de bolores e leveduras (UFC/g). A fim de atestar a qualidade microbiológica da maionese, foram realizados ensaios no tempo $0,1,2$ e no tempo final da validade do produto para contagem de bolores e leveduras (UFC/g). Foram utilizadas as metodologias $\mathrm{APHA}^{24}$, ISO 6579 25 , ISO $7251^{26}$, $\mathrm{AOAC}^{27}$.

\section{CARACTERÍSTICAS SENSORIAIS}

Foi realizado o exame das características sensoriais da amostra, por uma equipe de julgadores selecionados, quanto à acuidade visual. A amostra foi avaliada quanto à aparência, odor, textura/sensação na boca e sabor, à temperatura ambiente. Para quantificar as intensidades das características de odor, textura/sensação na boca e sabor, foi empregada uma escala de 0 a 10 em que o valor " 0 " corresponde a inexistente ou extremamente fraco, o valor " 5 " a moderado e o valor "10" a extremamente forte. Esta análise foi realizada no tempo 0 (18 dias), 1 (54 dias), 2 (94 dias) e no tempo final (123 dias) do prazo de validade do produto. A avaliação teve como objetivo verificar se há alterações significares nos atributos sensoriais durante o tempo de validade do produto.

Visando identificar alterações sensoriais ao longo do tempo, a maionese foi armazenada a $25^{\circ} \mathrm{C}$, desde a fabricação, após 18, 54, 94 e 123 dias da data de fabricação.

\section{TESTE DE ACEITABILIDADE}

Para a avaliação sensorial, foram recrutados 51 consumidores de maionese, com idade entre 18 e 50 anos, das classes sociais $\mathrm{A} / \mathrm{B} / \mathrm{C}$, segundo Critério Padrão de Classificação Econômica Brasil 201323. Cada consumidor recebeu uma porção de $15 \mathrm{~g}$ da amostra em prato branco, descartável, de $10 \mathrm{~cm}$ de diâmetro para facilitar a visualização do produto, espátula descartável, acompanhado de pão de forma para que a maionese fosse avaliada. Para a limpeza do palato, foi oferecida água mineral natural.

A avaliação quando à aceitabilidade foi realizada para os seguintes atributos: de modo geral, aparência, cor, aroma, consistência visual, consistência na boca e sabor, por meio de escala hedônica de nove pontos $(9=$ gostei muitíssimo, 5 = não gostei nem desgostei e 1 = desgostei muitíssimo); quanto à intensidade da acidez e do gosto salgado por meio de escalas do ideal de cinco pontos $(5=$ muito mais intenso do que eu gosto, $3=$ do jeito que eu gosto, $1=$ muito menos intenso do que eu gosto), e quanto à intenção de compra por meio da escala de atitude de 5 pontos $(5=$ certamente compraria; 3 = talvez sim talvez não compraria; 1 = certamente não compraria). Foi ainda solicitado aos consumidores que descrevessem o que mais gostaram e o que menos gostaram na amostra. Além das questões relacionadas à avaliação do produto, os consumidores responderam a questões pessoais e sobre hábitos de consumo de maionese. $\mathrm{O}$ teste foi conduzido em cabines individuais com iluminação de lâmpadas fluorescentes e equipado com o sistema computadorizado Compusense Five Versão 5.4 para coleta dos dados e obtenção de médias e frequências. Entre os resultados da escala do ideal e aceitabilidade de modo global foi aplicado Penalty Analysis.

\section{Resultados e Conclusões}

\section{ANÁLISES FÍSICO-QUÍMICAS}

Os resultados das análises físico-químicas encontramse disponíveis na Tabela 1, 2 e 3.

\section{ANÁLISE MICROBIOLÓGICA}

De acordo com os resultados, é possível concluir que a maionese de pequi encontra-se dentro dos padrões estabelecidos na RDC 12 de 2001, conforme pode ser visualizado na Tabela 4. 
Tabela 1. Resultados da análise físico-química da maionese de pequi.

\begin{tabular}{|c|c|c|c|}
\hline \multirow{2}{*}{ Determinação } & \multicolumn{3}{|c|}{ Resultado } \\
\hline & $/ 100 \mathrm{~g}$ & $/ 23 \mathrm{~g}$ & $\% V D$ \\
\hline Umidade e voláteis $(\mathrm{g})$ & $60,04(0,01) \mathrm{a}$ & 13,81 & - \\
\hline Cinzas $(\mathrm{g})$ & $2,41(0,01) \mathrm{a}$ & 0,55 & - \\
\hline Lipídeos totais $(\mathrm{g})$ & $27,26(0,03) \mathrm{a}$ & 6,27 & 11 \\
\hline Carboidratos totais $(\mathrm{g})$ & $8,95 b$ & 2,06 & 1 \\
\hline Calorias (kcal) & $287 \mathrm{c}$ & 66 & 3 \\
\hline Ácidos graxos livres (g/100g da fração lipídica expresso em ácido oleico) & $1,00(0,00) \mathrm{a}$ & - & - \\
\hline Índice de iodo (cgl/g da fração lipídica) & $93(1) \mathrm{a}$ & - & - \\
\hline Alfa-tocoferol (mg) & $3,55(0,16) \mathrm{a}$ & 0,82 & - \\
\hline Beta-tocoferol (mg) & $0,26(0,01) \mathrm{a}$ & 0,06 & - \\
\hline Gama-tocoferol (mg) & $6,05(0,60) \mathrm{a}$ & 3,69 & - \\
\hline Delta-tocoferol (mg) & $4,86(0,39) \mathrm{a}$ & 1,12 & - \\
\hline Tocoferol total (mg) & 24,73 & 5,69 & - \\
\hline Vitamina E (UI) & 6 & 1 & - \\
\hline Vitamina E expressa como alfa-tocoferol (mg) & 5,86 & 1,35 & 13 \\
\hline Beta-caroteno $(\mu \mathrm{g})$ & $22,96(0,15) \mathrm{a}$ & 5,28 & - \\
\hline Vitamina A (UI) & 13 & 3 & 0 \\
\hline Proteína $(\mathrm{Nx} 6,25)(\mathrm{g})$ & $1,34(0,01) \mathrm{a}$ & 0,31 & 0 \\
\hline Cálcio (mg) & $34,4(0,4) \mathrm{a}$ & 7,9 & 1 \\
\hline Ferro (mg) & $0,46(0,03)$ & 0,11 & 1 \\
\hline Fósforo (mg) & $51(2) \mathrm{a}$ & 12 & 2 \\
\hline Magnésio (mg) & $2,9(0,1) a$ & 0,7 & 0 \\
\hline Potássio (mg) & $26,4(0,5) \mathrm{a}$ & 6,1 & - \\
\hline Sódio (mg) & 775 (3)a & 178 & 7 \\
\hline
\end{tabular}

$U I=$ Unidade Internacional, $a-$ Média estimativa de desvio padrão, $b-$ Calculado por diferença: $100-(\mathrm{g} / 100 \mathrm{~g}$ unidade $+\mathrm{g} / 100 \mathrm{~g}$ cinzas $+\mathrm{g} / 100 \mathrm{~g}$ proteina $+\mathrm{g} / 100 \mathrm{~g}$ lipídeos totais), $c$-O valor calórico da amostra foi calculado pela soma das porcentagens de proteína e carboidratos multiplicados pelo fator 4 (kcal/g) somado ao teor de lipídeos totais multiplicado pelo $9(\mathrm{kcal} / \mathrm{g}), d$ - Area $x \%$ lipídeos $/ 100 x \mathrm{~F}$ de conversão $(F=0,956)$. Limite de detecção do método $=0,01 \mathrm{lg} / 100 \mathrm{~g}$.

Tabela 2. Composição de ácidos graxos da maionese de pequi.

\begin{tabular}{|c|c|c|c|}
\hline Ácido graxos (g) & $\mathbf{1 0 0} \mathbf{g}$ & $\mathbf{2 3} \mathbf{g}$ & $\mathbf{\%}$ VD \\
\hline Saturados & 5,08 & 1,17 & 5 \\
\hline Monoinsaturados & 8,15 & 1,87 & - \\
\hline Poli-insaturados & 12,52 & 2,88 & - \\
\hline Ômega 3 & 1,08 & 0,25 & - \\
\hline Ômega 6 & 11,44 & 2,63 & - \\
\hline Trans-isômeros totais & 0,24 & 0,03 & - \\
\hline N.I. & 0,03 & 0,01 & - \\
\hline
\end{tabular}


Tabela 3. Perfil de ácidos graxos da maionese de pequi.

\begin{tabular}{|c|c|c|c|}
\hline Composição em ácidos graxos & \% de Área & $\mathbf{( g / 1 0 0 g}) \mathbf{~}$ & $\mathbf{( g / 2 3 g})$ \\
\hline C14:0 mirístico & 0,11 & 0,03 & 0,01 \\
\hline C16:0 palmítico & 15,03 & 3,91 & 0,9 \\
\hline C16:1 ômega 7 palmítico & 0,36 & 0,09 & 0,02 \\
\hline C17:0 margárico & 0,08 & 0,02 & $<0,01$ \\
\hline C18:0 esteárico & 3,59 & 0,93 & 0,21 \\
\hline C18:1 ômega 9 oléico & 30,49 & 7,93 & 1,82 \\
\hline C18:2 ômega 6 trans t-linoléico & 0,56 & 0,15 & 0,03 \\
\hline C18:2 ômega 6 linoléico & 43,98 & 11,44 & 2,63 \\
\hline C20:0 araquídico & 0,28 & 0,07 & 0,02 \\
\hline C18:3 ômega 3 trasn t-linolênico & 0,33 & 0,09 & 0,02 \\
\hline C20:1 ômega 11 cis-11-eicosenónico & 0,49 & 0,13 & 0,03 \\
\hline C18:3 ômega 3 alfa linolênico & 4,15 & 1,08 & 0,25 \\
\hline C22:0 behênico & 0,33 & 0,09 & 0,02 \\
\hline N.I. & 0,1 & 0,03 & 0,01 \\
\hline C24:0 lignocérico & 0,12 & 0,03 & 0,01 \\
\hline
\end{tabular}

Tabela 4. Qualidade microbiológica da maionese de pequi.

\begin{tabular}{|c|c|c|c|c|}
\hline \multirow{2}{*}{ Determinação } & \multirow{2}{*}{ Método } & \multicolumn{3}{|c|}{ Resultado / Repetição } \\
\hline & & 1 & 2 & 3 \\
\hline Salmonella (em 25g) & $\begin{array}{c}\text { ISO } 6579 \text { (2007), AOAC } \\
(2005)\end{array}$ & ausente & ausente & ausente \\
\hline $\begin{array}{c}\text { Coliformes } \\
\text { termotolerantes (NMP/g) }\end{array}$ & ISO 7251 (2005) & $<3$ & $<3$ & $<3$ \\
\hline $\begin{array}{l}\text { Contagem total de } \\
\text { aeróbios mesófilos } \\
\text { (UFC/g) }\end{array}$ & APHA (2001) & $2,4 \times 103$ & $3,6 \times 103$ & $4,0 \times 103$ \\
\hline $\begin{array}{l}\text { Contagem de bolores e } \\
\text { leveduras (UFC/g) }\end{array}$ & APHA (2001) & $<102$ & $2,0 \times 102$ (est)a & $<102$ \\
\hline
\end{tabular}

Com relação à avaliação da vida de prateleira, a amostra foi avaliada por mais 3 tempos dentro do prazo de validade a contagem de bolores e leveduras (UFC/g). Os valores encontrados permaneceram os mesmos durante todo o período.

\section{CARACTERÍSTICAS SENSORIAIS}

A maionese de pequi foi avaliada quanto a aparência e para este atributo foi descrita como creme liso, brilhante e consistente de coloração amarela que lembra a coloração de mostarda, com partículas de condimentos de coloração escura avermelhada. Nos demais atributos, os julgadores pontuaram, de acordo com a escala de 0 a 10. Para o odor, foram atribuídos os seguintes valores: ácido (8), que lembra mostarda (6), condimentos (5) e ovo (4). Não foi detectado pelos julgadores nenhum odor estranho. Para a textura/sensação na boca a característica consistência recebeu nota 7, o aspecto oleoso nota 4, farinhento nota 4, levemente picante nota 3 e levemente adstringente nota 2 . Para o atributo sabor, foram pontuadas as características ácido (7), salgado (6), condimento (5-6), mostarda (56), doce (3-4), ovo (4) e óleo vegetal (3). Com relação ao sabor, nenhum julgador apontou a presença de sabor estranho. 
Com exceção da textura/sensação na boca cujo atributo farinhento sofreu alteração, as demais características sensoriais do produto nos tempos 0 e 1 se mantiveram estáveis. Para a aparência, foi descrita como creme liso, brilhante e consistente de coloração amarela que lembra a coloração de mostarda, com partículas de condimentos de coloração escura e avermelhada. O odor teve como descritores ácido (8), que lembra mostarda (6), condimentos (5) e ovo (4). Nenhum julgador encontrou a presença de odores estranhos. Para a textura/sensação na boca, o atributo consistência obteve o valor 7 , oleoso 4 , farinhento 4 no tempo 0 e farinhento 2 no tempo 1 , levemente picante 3 e levemente adstringente 2 . A característica ácida para sabor obteve 7, salgado 6, condimento 5-6, mostrada 5-6, doce 3-4, ovo 4 e óleo vegetal 3 . Também nenhum julgador percebeu a presença de sabores estranhos. Após 94 dias da data de fabricação, a alteração percebida pelos avaliadores em relação à avaliação anterior foi a ausência da sensação de produto farinhento. Após 123 dias, a alteração percebida na maionese de pequi em relação à avaliação anterior foi a presença de odor estranho (6) ao abrir a embalagem, lembrando a produto fermentado e, por esta razão, o produto não foi avaliado quanto à textura/sensação na boca e quanto ao sabor. Também foi percebida a presença de bolhas na maionese e fungos na rosca da tampa e do frasco. Nas amostras avaliadas, o lacre se destacou juntamente à tampa na abertura da embalagem. Na Figura 1, são apresentados os perfis sensoriais da maionese aos 18, 54, 94 e 123 dias com base nas características de odor, textura/sensação na boca e de sabor, quando avaliados.

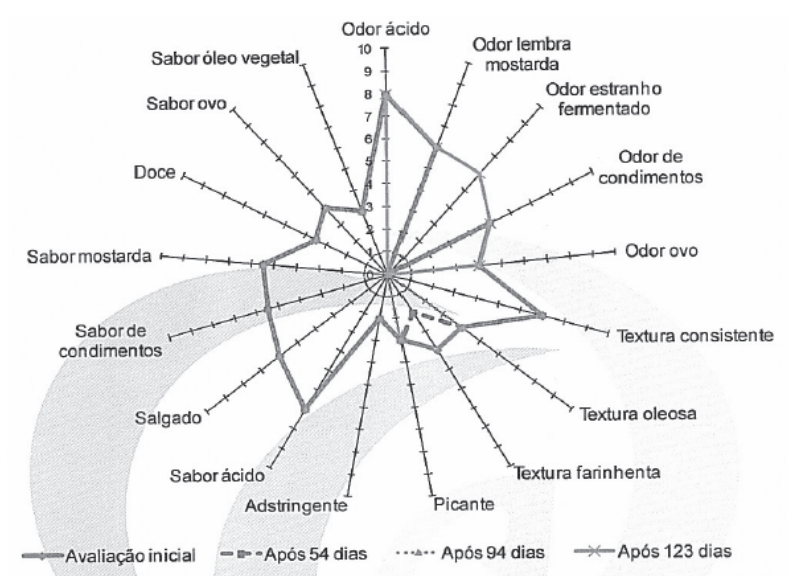

Figura 1. Perfis de odor, textura/sensação na boca e sabor da amostra de maionese de pequi aos 18, 54, 94 e 123 dias.

\section{TESTE DE ACEITABILIDADE}

Dentre os 51 consumidores que participaram do teste, 40 eram mulheres e 11 homens. As características do grupo quanto à faixa etária e classe social são apresentadas na Figura 2, e a frequência de hábitos de consumo é apresentada na Figura 3. Os resultados médios obtidos no teste de aceitabilidade, intensidade da acidez e do gosto salgado, alem da atitude de intenção de compra da maionese pelo grupo de consumidores que participou das avaliações estão apresentado na Tabela 5.

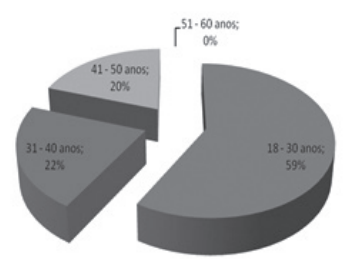

(a)

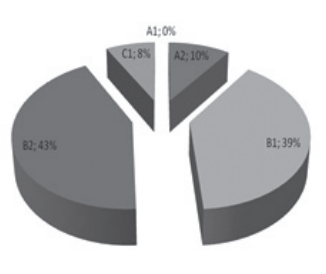

(b)
Figura 2. Faixa etária (a) e classe social (b) do grupo de consumidores que avaliou as amostras.

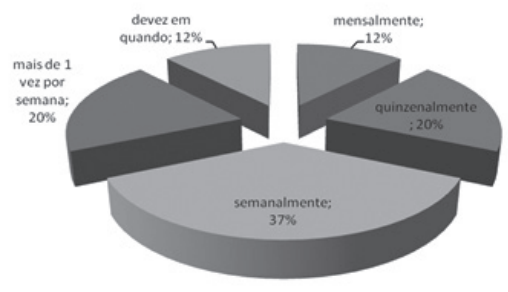

(a)
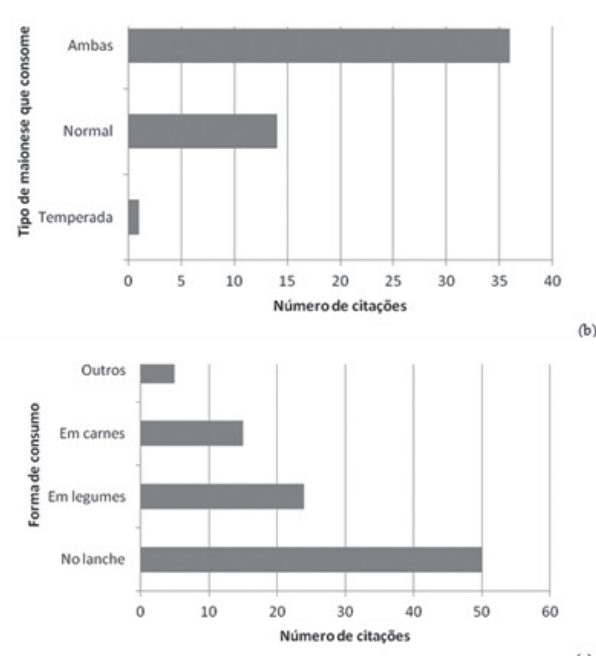

(c)

Figura 3. Frequência (a), tipo de maionese (b)e local de consumo (c) citados pelo do grupo de consumidores que avaliou a amostra. 
Tabela 5. Resultados* obtidos no teste para avaliação da maionese pelo grupo de consumidores quanto aos atributos avaliados.

\begin{tabular}{|c|c|c|}
\hline \multirow{4}{*}{ Maionese Regional - Tempo 0 } \\
\hline \multirow{4}{*}{ Aceitabilidade } & Aparência & $6,8(1,5)$ \\
\cline { 2 - 3 } & Cor & $6,6(1,5)$ \\
\cline { 2 - 3 } & Aroma & $6,6(1,4)$ \\
\cline { 2 - 3 } & Consistência visual & $7,2(1,4)$ \\
\cline { 2 - 3 } & $\begin{array}{c}\text { Consistência na } \\
\text { boca }\end{array}$ & $6,7(1,4)$ \\
\cline { 2 - 3 } & Sabor & $5,9(2,0)$ \\
\cline { 2 - 3 } & $\begin{array}{c}\text { Produto de modo } \\
\text { global }\end{array}$ & $6,5(1,4)$ \\
\hline \multirow{2}{*}{ Intensidade } & Acidez & $3,5(0,6)$ \\
\cline { 2 - 3 } & Gosto salgado & $3,0(0,6)$ \\
\hline Intenção de compra & $2,9(1,1)$ \\
\hline \multicolumn{2}{|c|}{} \\
\hline
\end{tabular}

* Resultados expressos com média (desvio - padrão)

Nas Figuras 4, 5 e 6 , são apresentadas as distribuições em frequência dos valores das escalas, atribuídos pelos consumidores para a intensidade da acidez e gosto salgado: acima do ideal (valores 5 e 4 das escalas), ideal (valor 3) e abaixo do ideal (valores 2 e 1 das escalas), bem como para a intenção de compra: intenção positiva (valores 5 e 4 das escalas), neutralidade (valor 3) e intenção negativa (valores 2 e 1 das escalas).

Observa-se que na Figura 4, a acidez da maionese foi avaliada como mais intensa que o ideal (muito mais ácido/ um pouco mais ácido do que eu gosto) para a maioria dos consumidores. Esta característica afetou negativamente a aceitabilidade do produto, conforme ilustrado na Figura 6.

Na Figura 5, observa-se que as maiores frequências dos valores das escalas atribuídos pelos consumidores para a intensidade do gosto salgado são as neutras (do jeito que eu gosto). Esta característica não afetou a aceitabilidade do produto conforme ilustrado na Figura 6. Quanto à intenção de compra, a amostra obteve média próxima "talvez comprasse, talvez não comprasse". Por meio da Figura 5, observam-se maiores frequências negativas (provavelmente/certamente não compraria) dos valores das escalas atribuídos pelos consumidores para a intenção de compra.

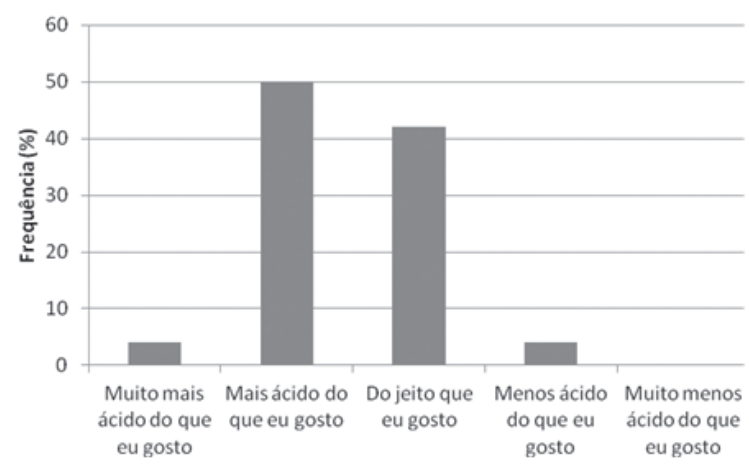

Figura 4. Distribuição em frequência dos valores da escala atribuídos para a intensidade da acidez, pelo grupo de consumidores que avaliou a maionese.

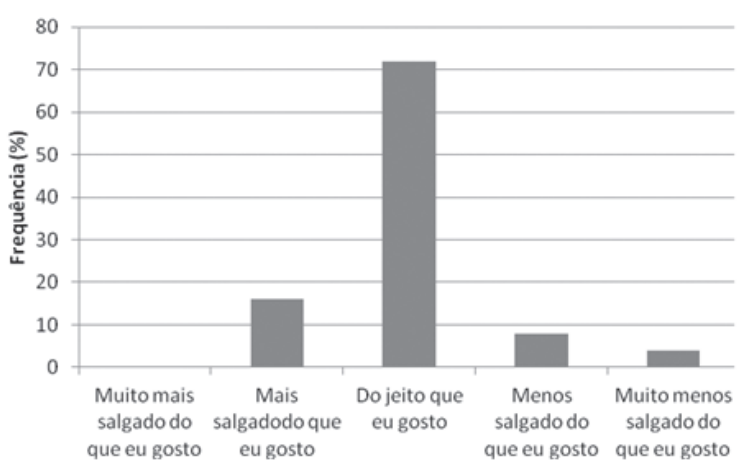

Figura 5. Distribuição em frequência dos valores da escala atribuídos para a intensidade do gosto salgado, pelo grupo de consumidores que avaliou a maionese.

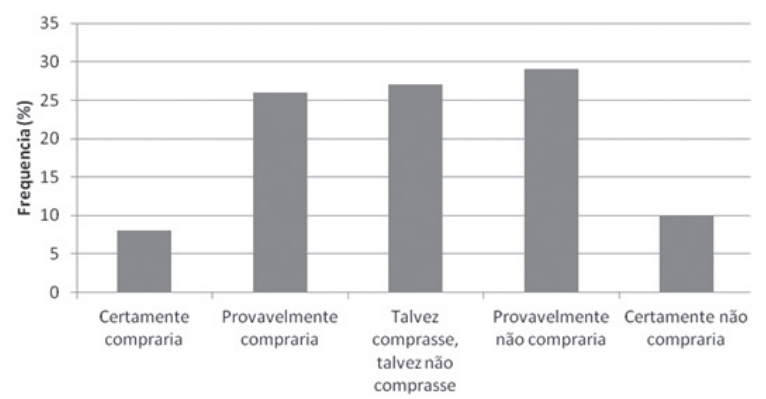

Figura 6. Distribuição em frequência dos valores da escala atribuídos para a intenção de compra, pelo grupo de consumidores que avaliou a maionese. 
$\mathrm{Na}$ Figura 7, é ilustrada a diminuição da aceitabilidade global em relação à intensidade da acidez e do gosto salgado. Em todos os atributos avaliados quanto à aceitabilidade, a maionese obteve médias situadas entre "gostei pouco" e "gostei" na escala empregada, exceto para o sabor, com média próxima de "gostei pouco". Quanto à intensidade da acidez, a maionese obteve média situada entre "do jeito que eu gosto" e "mais ácido do que eu gosto", e para a intensidade do gosto salgado, média correspondente a "do jeito que eu gosto".

A Figura 7 ilustra de forma gráfica o resultado da Penalty Analysis para a maionese. A zona crítica é onde os atributos são percebidos como mais ou menos intensos por um percentual acima de $20 \%$ dos consumidores e que impactam no decréscimo maior do que meio ponto quanto à aceitabilidade global. $\mathrm{O}$ gráfico apresenta o atributo acidez na intensidade mais ácido do que o ideal nesta zona crítica. A acidez menos intensa do que o ideal e o gosto salgado, mais ou menos intenso que o ideal, produziram impacto em menos que $20 \%$ dos consumidores e a diminuição em menos que meio ponto na aceitabilidade global.

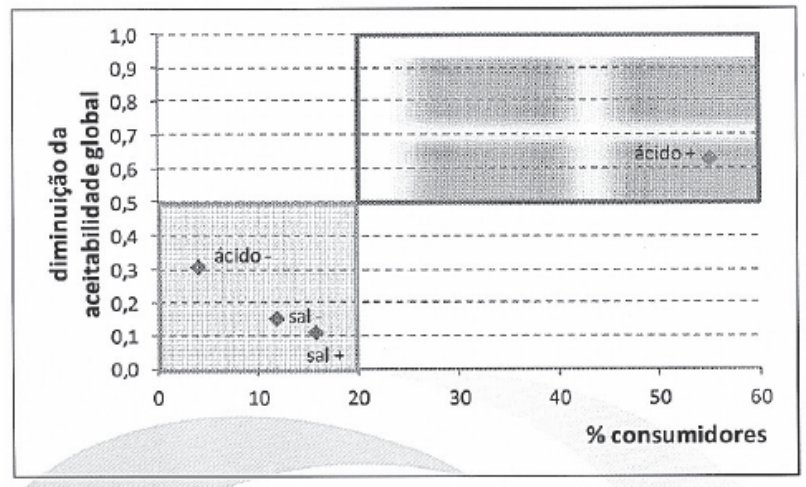

Figura 7. Aceitabilidade global em relação à intensidade da acidez e do gosto salgado percebido pelos consumidores.

Nas Tabelas 6 e 7 são apresentadas as menções dos gostos e desgostos, descritos pelos consumidores. A maionese apresentou o total de frequências de menções negativas superior, cabendo destacar o sabor, em geral, como uma característica negativa da amostra, por ter recebido 46 menções negativas pelo grupo de consumidores.
Tabela 6. Gostos descritos pelos consumidores em relação à maionese (números indicam frequência com que foram citados).

\begin{tabular}{|l|c|}
\hline Gostos & Maionese \\
\hline Aparência, cor, brilho & 15 \\
\hline Aroma & 7 \\
\hline Sabor, sabor residual, tempero & 12 \\
\hline Acidez & 2 \\
\hline Gosto salgado & 1 \\
\hline $\begin{array}{l}\text { Textura, consistência, } \\
\text { espalhabilidade }\end{array}$ & 21 \\
\hline $\begin{array}{l}\text { TOTAL DE MENSÕES } \\
\text { POSITIVA }\end{array}$ & $\mathbf{5 8}$ \\
\hline
\end{tabular}

Tabela 7. Desgostos descritos pelos consumidores em relação à maionese (números indicam frequência com que foram citados).

\begin{tabular}{|l|c|}
\hline Gostos & Maionese \\
\hline Aparência, cor & 8 \\
\hline Aroma & 5 \\
\hline Sabor & 15 \\
\hline Gosto doce & 7 \\
\hline $\begin{array}{l}\text { Sabor artifical, tempero, } \\
\text { amargo, estranho }\end{array}$ & 13 \\
\hline Acidez & 11 \\
\hline Textura, consistência, ardência & 6 \\
\hline $\begin{array}{l}\text { TOTAL DE MENSÕES } \\
\text { POSITIVA }\end{array}$ & $\mathbf{6 5}$ \\
\hline
\end{tabular}

\section{Conclusão}

A maionese de pequi manteve-se estável ao longo de 94 dias, com exceção da percepção da sensação de farinhento que não foi mais notada, o que alterou positivamente o produto. Aos 123 dias, foi percebido, imediatamente ao abria a embalagem, um odor estranho que lembra a característica de fermentação. Esta característica de odor impactou negativamente o produto, pois não era a mesma característica acética percebida desde a avaliação inicial. O destacamento do lacre e a presença de fungo na rosca possivelmente foram as razões do odor estranho. É importante salientar que, ao estipular o prazo de validade de um produto, a empresa deve levar em consideração o risco que está disposto a 
assumir quanto à possível percepção dos consumidores em relação às alterações sensoriais que podem ocorrer. Dessa forma, para garantir o padrão de qualidade do produto, é de extrema importância a qualificação dos fornecedores, neste caso, principalmente, do fornecedor de óleo de pequi. É fato que muitas vezes o modo como é feito o beneficiamento dos frutos do cerrado não garante a segurança microbiológica, tendo em vista que não é realizado qualquer tratamento térmico. Portanto, para revolver este problema, é importante que os fornecedores passem por capacitação em boas práticas e que haja constantemente acompanhamento dos processos produtivos que são adotados.

\section{Referências}

1. Min, D. B.; Boff, J. M. Lipid Oxidation of Edible Oil. In: Akoh, C. C.; Min, D. B. (ed). Food Lipids: Chemistry, Nutrition, and Biotechnology, 2002.

2. Depree, J. A., Savage, G. P. Trends in Food Science and Technology, 2001.

3. Haenhuttl, G. L. Overview of food emulsifiers. In: Hasenhuettl, G. L., Hartel, R. W. (Ed.). Food Emulsifiers and their Applications. 2008.

4. Narsimhan, G.; Wang, Z. Guidelines for processing emulsionbased foods. In: Hasenhuettl, G. L., Hartel, R .W. (ed.). Food Emulsifiers and their Applications. 2008.

5. Sec. 169.140 Mayonnaise. Code of Federal Regulations. 2002.

6. Garcia, K.; Sriwattana, S.; NO, H. K.; Corredor, J. A. H.; Prinyawiwatkul, W. Journal of Food Science, 2009, 248-254.

7. Brasil. Agência Nacional de Vigilância Sanitária. Resolução RDC $\mathrm{n}^{\circ} 276$, de 22 de setembro de $\mathbf{2 0 0 5}$.

8. Mancini, F.; Montanari, L.; Peressini, D.; Fantozzi, P. Lwt-Food Science and Technology, 2002, 517-525.

9. Dolz, M., Hernandez, M. J., Delegido, J. Journal of Applied Polymer Science, New York, 2006, 897-903

10. Shen, R.; Luo, S.; Dong, J. Food Chemistry, 2011, 65-71.

11. Chouard, G.; Rettenmaier, J.; Shne, S. 100\%. Innovations in Food Technology, 2005, 98-100.

12. Chen, M. B. Academic Periodical of Farm Products Processing, 2005, 22-24.

13. Saito, S., Takeshita, M., Tomonobu, K., Kudo, N., Shiiba, D., Hase, T. Nutrition, 2006, 174-178.

14. Izidoro, D. R.; Scheer, A. P.; Sierakowski, M. R.; Haminiuk, C. W. I. Lwt - Food Science and Technology, Zurich, 2008, 1018-1028.
15. Godoy, H. T.; Rodriguez-Amaya, D. B. Journal of Agricultural and Food Chemistry, 1994, 1306-1313.

16. Zenebon, O.; Pascuet, N. S. (coord.). Métodos físico-químicos para análise de alimentos. Instituto Adolfo Lutz, 2005.

17. Horwitz, W.; Latimer Jr.; George, W. (ed.). Official Methods of Analysis of the Association of Official Analytical Chemists, AOAC, 2010.

18. Usp. Tabela Brasileira de Composição de Alimentos, 2008.

19. HorwitZ, W. (ed). Official Methods of Analysis of the Association of Official Analytical Chemists. 18th. AOAC, 2005, 15-18.

20. Firestone, D. (ed.). Official Methods and Recommended Practices of the American Oil Chemists Society. AOCS, 2009.

21. Carvalho, P. R. N.; Collins, C. A.; Rodriguez-Amaya, D. B. Comparison of provitamin A determination by normal-phase gravity-flow column chromatography and reversed phase high performance liquid chromatography, 1992.

22. Brubacher, G. Muller-Mulot, W.; Southgate, D. A. T. Methods for the determination of vitamins in food - recommended by COST 91, 1985.

23. ABEP. Associação Brasileira De Empresas De Pesquisa. Critérios de Classificação Econômica Brasil, 2013.

24. APHA. Compedium of Methodos Microbiological Examination of Food, 2001.

25. ISO. International Standard ISO 6579, 2007.

26. ISO. International Standard ISO 7251, 2005.

27. AOAC. Official Methods of Analysis, 2005.

\section{Flávia I. R. O. Araújo*, Marina S. Araújo, Adriana A. Carvalho \& Karolline F. Siqueira.}

Instituto SENAI de Tecnologia em Alimentos e Bebidas,-- Rua Professor Lázaro Costa nº 348, Vila Canaã, CEP: 74415-420, Goiânia, Goiás, Brasil

*E-mail: flaviaisaraujo.senai@sistemafieg.org.br 